\title{
A Suitable Power Transfer Control System for Interconnection Converter of DC Microgrids
}

\author{
Mishel Mahmoodi, Reza Noroozian, Gevorg B. Gharehpetian, Mehrdad Abedi \\ Electrical Engineering Department, Amirkabir University of Technology \\ No. 424, Hafez Ave., 15914, Tehran, Iran \\ Phone number: +9821 66466009, email: grptian@aut.ac.ir
}

\begin{abstract}
The operation and control strategies for interconnection of DC microgrids have not been studied in previous researches. In this paper, an electrical model has been developed for DC microgrids and a suitable control system has been proposed for a DC/DC converter connecting two DC microgrids. Simulation results indicate the effectiveness of the proposed control strategy in power flow control and the cancellation of interactions between two DC microgrids.
\end{abstract}

\section{Keywords}

DC Microgrid, Distributed Generation, Droop Control, Hysteresis Current Control.

\section{Introduction}

The interest in Distributed Generation (DG) is increasing due to technical, economical, reliability and environmental merits. As a result, a significant share of electricity will be generated and consumed locally in future electric power systems. Local aggregation of DG systems and electrical loads results in a Microgrid $(\mu \mathrm{G})$. In order to meet energy, reliability, power quality, power back-up and peak shaving needs and to allow sharing of resources within a common infrastructure, multiple $\mu \mathrm{Gs}$ could be interconnected resulting in a power park [1]. The DC Microgrid (DC $\mu \mathrm{G})$ concept and consequently, DC power parks have provided a new paradigm for future distribution power systems. This is due to the fact that modern DG systems (e.g., fuel cells, microturbines, photovoltaic arrays and wind power systems) and modern electrical loads (e.g., sensitive loads, electronic loads and AC drives) have DC link stages for interconnection to the AC distribution network. As a result, $\mathrm{DC} \mu \mathrm{Gs}$ provide the best solution for the aggregation of these devices by integrating their DC power link stages. Previous researches have shown that $\mathrm{DC} \mu \mathrm{Gs}$ are preferable to both power frequency and high frequency AC $\mu \mathrm{Gs}$ from various technical, economical and reliability viewpoints [2]-[7].
The interconnection of DC $\mu \mathrm{Gs}$ has not been studied in previous researches. A possible solution for interconnection of DC $\mu$ Gs could be the use of DC cables as their direct DC links. However, these links will result in the following disadvantages:

- Effective control of the DC link power flow will require considerable modifications in the design of controllers in both $\mathrm{DC} \mu \mathrm{Gs}$ and a supervisory control system to monitor the DC voltage changes at both DC $\mu \mathrm{Gs}$.

- Disturbances in one DC $\mathrm{DG}$ will instantaneously affect the other $\mathrm{DC} \mu \mathrm{G}$ through the DC link.

- Design of controllers in each $\mathrm{DC} \mu \mathrm{G}$ will considerably be affected by dynamic properties of the DC link and the other DC $\mu \mathrm{G}$.

- $\mu \mathrm{Gs}$ will be designed and controlled to meet local requirements according to their own independent operational standards and reliability and power quality guidelines [1], [4]-[7]. As a result, DC $\mu$ Gs will most probably have different DC voltage levels. DC $\mu \mathrm{Gs}$ with different DC voltage levels can not be connected to each other by direct DC links.

As a result, DC cables are not an acceptable solution for interconnection of $\mathrm{DC} \mu \mathrm{Gs}$. A modern solution for the interconnection of power systems has been the Power Electronic Conversion System (PESC) which provides the following benefits as compared to the direct DC link interconnection method:

- Added power flow control,

- Increased system flexibility and controllability,

- Improved system stability.

Consequently, a DC/DC converter named Interconnection Converter (ICC) has been used in this paper for the interconnection of two DC $\mu \mathrm{Gs}$. The DC/DC ICC can simply interconnect two $\mathrm{DC} \mu \mathrm{Gs}$ with different DC voltage levels. The main goal of this research is to develop a suitable control system for the DC/DC ICC which should 
provide proper power flow control and the cancellation of interactions between the $\mathrm{DC} \mu \mathrm{Gs}$.

\section{Operation and Control of a $\mathrm{DC} \mu \mathrm{G}$}

The typical structure of a $D C \mu G$ is shown in Fig. 1 .

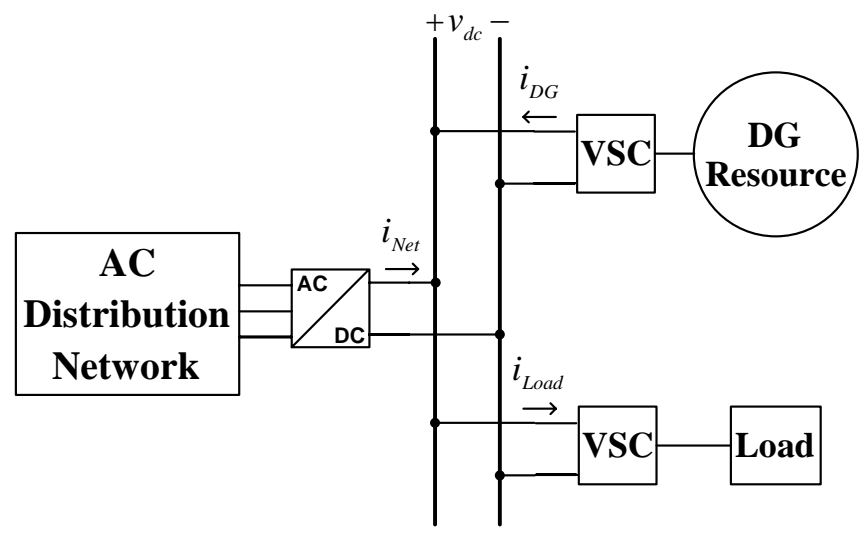

Fig. 1. General structure of $\mathrm{DC} \mu \mathrm{G}$

All power electronic converters of the $\mathrm{DC} \mu \mathrm{G}$ are Voltage Source Converter (VSC) systems. Note that in order to avoid a cut set of voltage or current sources at converter switching, one side of a VSC should have a capacitive termination and the other side of the VSC should have an inductive termination. The $\mathrm{DC} \mu \mathrm{G}$ has a common capacitive DC terminal for its VSCs. The AC distribution network, the DG system and the load are connected to the inductive terminals of their interface VSCs. In this paper, each converter of the $\mathrm{DC} \mu \mathrm{G}$ is named considering its inductive side subsystem, i.e. the network converter, the DG converter and the load converter.

Previous researches have developed several operation and control strategies for subsystems of a $\mathrm{DC} \mu \mathrm{G}$. Considering technical and economical issues, the following operation and control strategies have been selected for $\mathrm{DC} \mu \mathrm{Gs}$ of this paper:

- The DC bus voltage should be adjusted within its specified limits in order to meet the VSCs requirements [4]-[7].

- The DG system controller should be designed to meet its technical and economical constraints such as maximum/optimum power/efficiency operation [4], [5].

- The load voltage should be regulated to meet its requirements [4]-[7].

- The $\mathrm{DC} \mu \mathrm{G}$ operation and control should be independent from fast communication systems [4]-[6].

- The DG and the load should be decoupled from disturbances of the neighboring subsystems [7].

To achieve all the above characteristics, the following control systems have been proposed in [2] and [3]:
- The network converter incorporates a Hysteresis Current Control (HCC) Pulse Width Modulation (PWM) system whose reference current is specified by a DC $\mu \mathrm{G}$ bus voltage droop controller.

- The DG converter incorporates an HCC PWM system whose reference current is specified by a local DG controller which considers the DG resource technical and economical generation requirements.

- The load converter incorporates a linear PWM system whose reference signal is specified by a local load controller which considers the load technical and economical supply requirements.

Note that each local controller of a $\mu G$ should be coordinated by the $\mu \mathrm{G}$ central controller which is responsible for the optimization of the $\mu G$ operation [1], [8].

\section{DC $\mu$ G Modeling}

According to the load-generation voltage control concept in DC distribution systems, the original and large signal values of the $\mathrm{DC} \mu \mathrm{G}$ bus voltage are the same [3]. This is due to the fact that the capacitive terminals of VSCs do not include high frequency switching waveforms. As $\mathrm{DC} \mu \mathrm{G}$ bus voltages are the only signals from the $\mathrm{DC} \mu \mathrm{Gs}$ which interact with the DC/DC ICC, detailed and large signal modeling of the $\mathrm{DC} \mu \mathrm{Gs}$ would provide the same results for studying the DC/DC ICC. As a result, the large signal model of the $\mathrm{DC} \mu \mathrm{G}$ has been developed in this paper. Note that the large signal model of a power electronic system is derived from its detailed model by time averaging of high frequency switching waveforms.

The HCC reference currents of the network converter and the DG converter are smooth PWM signals due to slower dynamics of the $\mathrm{DC} \mu \mathrm{G}$ voltage droop controller and the local DG controller in comparison to the HCC fast switching operation. Thus, the HCC VSC current error is normally maintained within the hysteresis band. As a result, the HCC VSC current is equal to its reference current at frequencies much lower than the switching frequency. In other words, the large signal value of the HCC VSC output current is equal to its reference current. Thus, the large signal behavior of the network converter and the DG converter are merely determined by the $\mathrm{DC} \mu \mathrm{G}$ voltage droop controller and the local DG controller, respectively.

The PWM reference voltage of the load converter is a smooth signal due to implementation of linear regulators and slower dynamics of the local load controller in comparison to the voltage PWM fast switching operation. Thus, the load terminal voltage is equal to its reference voltage at frequencies much lower than the switching frequency. In other words, the large signal value of the load voltage is equal to its reference voltage. As a result, the large signal behavior of the load converter is merely determined by the local load controller. 
As modeling of the local DG and load controllers is not required for purposes of this research, the DG and the load systems have been modeled as independent current sources in the large signal modeling of the $\mathrm{DC} \mu \mathrm{G}$. The capacitive DC bus is assumed to be lossless and has been modeled by an equivalent capacitor named DC bus capacitor $C_{d c}$ which represents the total required DC bus capacitor for the $\mathrm{DC} \mu \mathrm{G}$ VSCs. As a result, for the $\mathrm{DC} \mu \mathrm{G}$ shown in Fig. 1 we have:

$$
i_{N e t}=\frac{V_{r e f}-v_{d c}}{R_{d}}=C_{d c} \frac{d v_{d c}}{d t}+i_{\text {Load }}-i_{D G}
$$

where $i_{\text {Net }}$ is the network converter current, $V_{\text {ref }}$ is the reference DC bus voltage, $v_{d c}$ is the DC bus voltage and $R_{d}$ is the droop coefficient. Using (1), we have:

$$
P_{\text {Net }}=V_{d c} \cdot\left(\frac{V_{r e f}-V_{d c}}{R_{d}}\right)=\frac{\delta(1-\delta)}{R_{d}} \cdot V_{r e f}^{2}
$$

where $P_{\text {Net }}$ is the steady state active power of the network converter, $V_{d c}$ is the steady state DC bus voltage and $\delta$ is the voltage droop.

The droop coefficient is selected to obtain an acceptable $\delta$ at rated power condition of the network converter. Thus, using (2), $R_{d}$ can be obtained by the following equation:

$$
R_{d}=\frac{\delta_{n}\left(1-\delta_{n}\right)}{P_{\text {Net, rated }}} \cdot V_{\text {ref }}^{2}
$$

where $\delta_{n}$ is the nominal voltage droop and $P_{\text {Net,rated }}$ is the rated power of the network converter.

Unexpected changes of active power in $\mathrm{DC} \mu \mathrm{G}$ can result in out of range DC bus voltage and the shutdown of the $\mathrm{DC} \mu \mathrm{G}$. In order to prevent unexpected unbalancing of active power in a $\mathrm{DC} \mu \mathrm{G}$, the installation of power leveling units such as flywheels has been proposed in [4]. Power leveling units are costly and have complicated system operation and control. A new design approach is used in this research which eliminates the need for power leveling units in a DC $\mu \mathrm{G}$. In this paper, $P_{\text {Net,rated }}$ is proposed to be selected equal to maximum possible change of active power in the DC bus considering all operating conditions of DG systems and loads. In other words, the maximum value of the power injected to and absorbed from the DC bus is chosen for $P_{\text {Net,rated }}$. In this way, the DC voltage droop controller would maintain the DC bus voltage within the specified limits in all conditions. In previous papers [2], [3] of the authors, the rated power of the network converters have been selected equal to maximum value of total DG power and total load power which has resulted in effective active power balancing in all operating conditions of DG resources and loads without requiring power leveling units. In interconnected $\mathrm{DC} \mu \mathrm{Gs}$ of this research, the power transfer between $\mathrm{DC} \mu \mathrm{Gs}$ is proposed to be considered in the selection of the rated power of network converters in order to take all possible operation condition into account.

Using (1), the characteristic polynomial of the $\mathrm{DC} \mu \mathrm{G}$ voltage control system is obtained as follows:

$$
R_{d} C_{d c} \mathrm{~s}+1=T \mathrm{~s}+1
$$

where $\mathrm{s}$ is the Laplace transform operator and $T$ is the time constant of the DC voltage droop controller. Using (4), $C_{d c}$ is designed to give the DC voltage droop controller a specified $T$ as follows:

$$
C_{d c}=\frac{T}{R_{d}}
$$

The developed large signal model of the $\mathrm{DC} \mu \mathrm{G}$ is illustrated in Fig. 2.

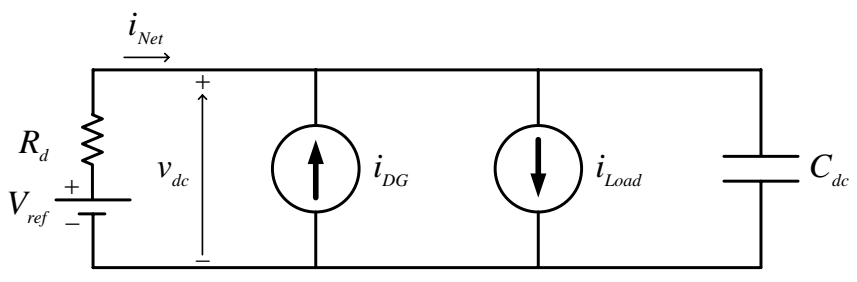

Fig. 2. $\mathrm{DC} \mu \mathrm{G}$ model

As shown in Fig. 2, the network converter is modeled using (1) as a DC voltage source of $V_{\text {ref }}$ in series with a resistor of $R_{d}$. The DG and load systems are modeled as independent current sources of $i_{D G}$ and $i_{\text {Load }}$, respectively. As explained before, the large signal modeling of the $\mathrm{DC} \mu \mathrm{Gs}$ in this paper is just for simplification and it is not an approximation.

\section{DC Power Park}

Fig. 3 illustrates the DC power park which has been studied in this paper.

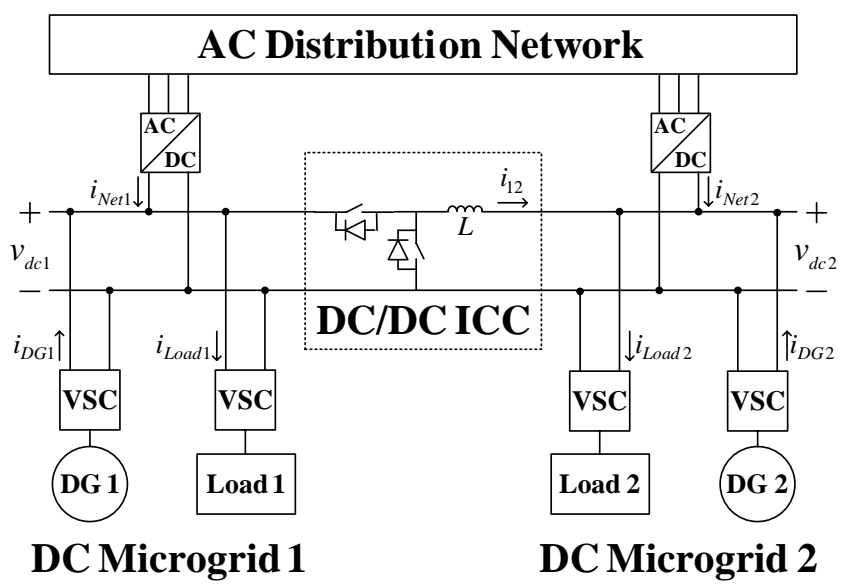

Fig. 3. DC power park 
This DC power park includes two DC $\mu \mathrm{Gs}$ named DC $\mu \mathrm{G} 1$ and DC $\mu \mathrm{G} 2$ which have been connected by a DC/DC ICC. A suitable control system should be developed for the DC/DC ICC in this section. DC $\mu \mathrm{G} 1$ and DC $\mu \mathrm{G} 2$ are assumed to have the general structure of $\mathrm{DC} \mu \mathrm{Gs}$ and $\mathrm{DC} \mu \mathrm{G} 1$ is assumed to have a higher DC voltage level than DCHG2. The DC/DC ICC has a DC/DC VSC topology with IGBT switches. For proper switching, operation and control of a DC/DC VSC, the DC voltage level at the capacitive terminal must be higher than the DC voltage level at the inductive terminal. As a result, the inductor $L$ in Fig. 3 has been installed in the $\mathrm{DC \mu G} 2$ side of the DC/DC ICC.

Fig. 4 illustrates the DC power park model. The losses of the connecting DC cables have not been considered for the interconnection of DC $\mu \mathrm{Gs}$. DC $\mu \mathrm{G} 1$ and $\mathrm{DC} \mu \mathrm{G} 2$ have been modeled using the large signal model of $\mathrm{DC} \mu \mathrm{Gs}$. According to the goals of this research, operation and control of the DC/DC ICC should be studied. As a result, detailed model of the DC/DC ICC has been used for modeling of the DC power park in this paper.

Considering technical and economical issues which are generally taken into account for power systems, the following points are assumed to design a suitable control system for the DC/DC ICC:

- $\quad$ Proper regulation of power flow between the $\mathrm{DC} \mu \mathrm{Gs}$

- Cancellation of interactions between the DC $\mu \mathrm{Gs}$

\section{Proposed Control System for DC/DC ICC}

The control system of the DC/DC ICC controller should have a fast dynamic response to changes of scheduled transfer power reference in order to properly regulate the power flow between the DC $\mu \mathrm{Gs}$. Furthermore, considering the possible DC voltage changes, the control system of the DC/DC ICC should be insensitive to these variations in both DC $\mu \mathrm{Gs}$. As a result, the DC/DC ICC control system should have the following characteristics:

- $\quad$ Fast dynamic response

- Insensitivity to system parameters variations
HCC is the simplest PWM system which has the above characteristics [9]. Thus, HCC has been used for the DC/DC ICC and its reference current is proposed to be calculated as follows:

$$
i_{12, \text { ref }}=\frac{P_{12, \text { ref }}}{v_{d c 2}}
$$

where $i_{12 \text {,ref }}$ is the HCC reference current and $P_{12 \text {,ref }}$ is the scheduled transfer power reference.

It must be noted that $i_{12 \text {,ref }}$ is the reference current for control of $i_{12}$ shown in Fig. 3. $i_{12 \text {,ref }}$ and $i_{12}$ are the inputs of a two level hysteresis comparator in the HCC system. As it can be seen, (6) is based on an instantaneous power regulation resulting in faster dynamic response than average power regulation methods.

The switching frequency of HCC systems is variable. Thus, the maximum switching frequency of the DC/DC ICC should be limited to an acceptable value. This issue is considered in the design of the inductor $L$ in Fig. 4. In an arbitrary switching cycle of the DC/DC ICC, the following equation is obtained according to the HCC concept:

$$
h=i_{12, \max }-i_{12, \min }=\frac{V_{d c 1}-V_{d c 2}}{L f_{s w}} D
$$

and

$$
D=\frac{V_{d c 2}}{V_{d c 1}}=\frac{1-\delta_{2}}{1-\delta_{1}} \cdot \frac{V_{\text {ref } 2}}{V_{\text {ref } 1}}
$$

where $h$ is the fixed hysteresis band, $i_{12 \text {,max }}$ is the maximum value of $i_{12}, i_{12 \text {,min }}$ is the minimum value of $i_{12}$, $f_{s w}$ is the switching frequency and $D$ is the duty ratio.

Thus, switching frequency of the DC/DC ICC is obtained as a function of $\delta_{1}$ and $\delta_{2}$ by the following equation:

$$
f_{s w}=\frac{\left(1-\delta_{2}\right) V_{r e f 2}}{L h} \cdot\left(1-\frac{1-\delta_{2}}{1-\delta_{1}} \cdot \frac{V_{r e f 2}}{V_{r e f 1}}\right)
$$

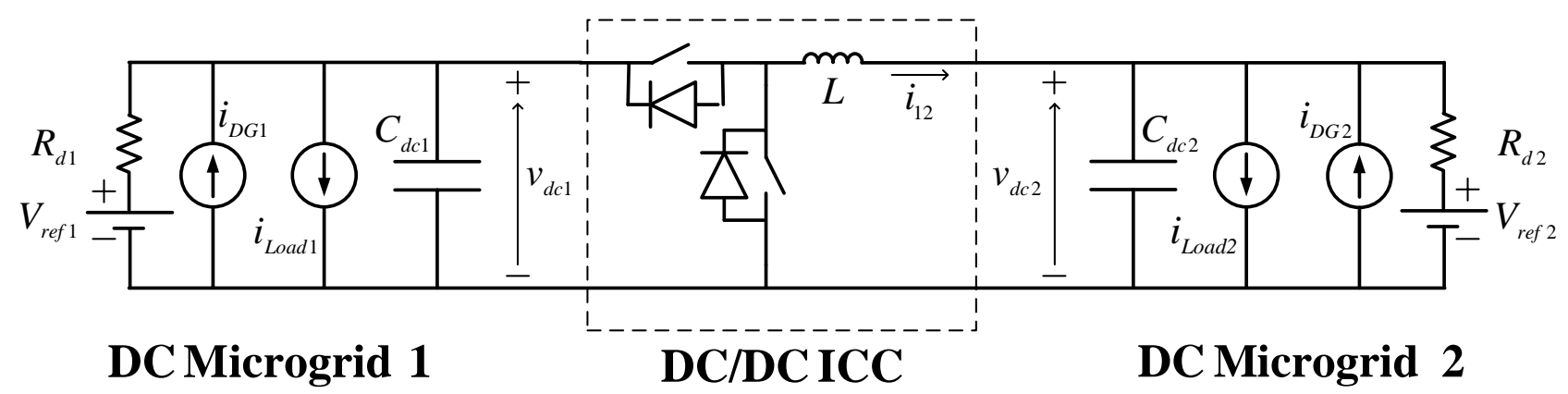

Fig. 4. DC power park model 
Using (9), the maximum value of $f_{s w}$ is obtained considering the following conditions:

$$
\left\{\begin{array}{l}
\delta_{1}=-\delta_{n 1} \\
\delta_{2}=1-\frac{1+\delta_{n 1}}{2} \cdot \frac{V_{r e f 1}}{V_{\text {ref } 2}}
\end{array}\right.
$$

Substituting (10) into (9), the inductor $L$ can be obtained as follows:

$$
L=\frac{V_{r e f 1}}{4 h f_{s w, n}} \cdot\left(1+\delta_{n 1}\right)
$$

where $f_{s w, n}$ is the acceptable switching frequency of the DC/DC ICC.

\section{Simulation Results}

The system shown in Fig. 4 has been modeled and simulated by PSCAD/EMTDC. The parameters given in Table I have been selected for DC $\mu \mathrm{Gs}$. The parameters of the DC/DC ICC are given in Table II. The system parameters calculated from the design procedure of this paper have been listed in Table III.

TABLE I. - Parameters of DC $\mu \mathrm{Gs}$

\begin{tabular}{|c|c|c|}
\hline Parameter & DC $\mu \mathrm{G} 1$ & DC $\mu \mathrm{G} 2$ \\
\hline$V_{\text {ref }}$ & $600 \mathrm{~V}$ & $270 \mathrm{~V}$ \\
\hline$\delta_{n}$ & 0.05 & 0.05 \\
\hline$T$ & $20 \mathrm{~ms}$ & $20 \mathrm{~ms}$ \\
\hline DG rated power & $60 \mathrm{~kW}$ & $10 \mathrm{~kW}$ \\
\hline Load rated power & $30 \mathrm{~kW}$ & $20 \mathrm{~kW}$ \\
\hline
\end{tabular}

TABLE II. - Parameters of DC/DC ICC

\begin{tabular}{|c|c|}
\hline$P_{12, \text { ref }}$ & $(-15)$ to $(+35) \mathrm{kW}$ \\
\hline$h$ & $5 \mathrm{~A}$ \\
\hline$f_{s w, n}$ & $10 \mathrm{kHz}$ \\
\hline
\end{tabular}

TABLE III

CALCULATED SYSTEM PARAMETERS

\begin{tabular}{|c|c|c|c|}
\hline \multirow{3}{*}{$\mathrm{DC} \mu \mathrm{G} 1$} & $R_{d}$ & 0.228 & (3) \\
\cline { 2 - 4 } & $C_{d c}$ & $87.72 \mathrm{mF}$ & (5) \\
\hline \multirow{2}{*}{$\mathrm{DC} \mu \mathrm{G} 2$} & $R_{d}$ & 0.07695 & (3) \\
\cline { 2 - 4 } & $C_{d c}$ & $259.91 \mathrm{mF}$ & (5) \\
\hline ICC & $L$ & $3.15 \mathrm{mH}$ & (11) \\
\hline
\end{tabular}

Note that considering the proposed design approach of this paper, the rated powers of the network converters have been selected as follows:

and

$$
P_{\text {Net1, rated }}=\max \{60+15,30+35\}=75 \mathrm{~kW}
$$

$$
P_{\text {Net } 2 \text {,rated }}=\max \{10+35,20+15\}=45 \mathrm{~kW}
$$

\section{A. Changes in Scheduled Transfer Power Reference}

In this section, the system performance under changes of $P_{12, \text { ref }}$ is studied. The DG and load powers in both $\mathrm{DC} \mu \mathrm{Gs}$ are assumed to have rated values of Table I. Fig. 5 illustrates $P_{12 \text {,ref }}$ and the instantaneous active power of the DC/DC ICC.

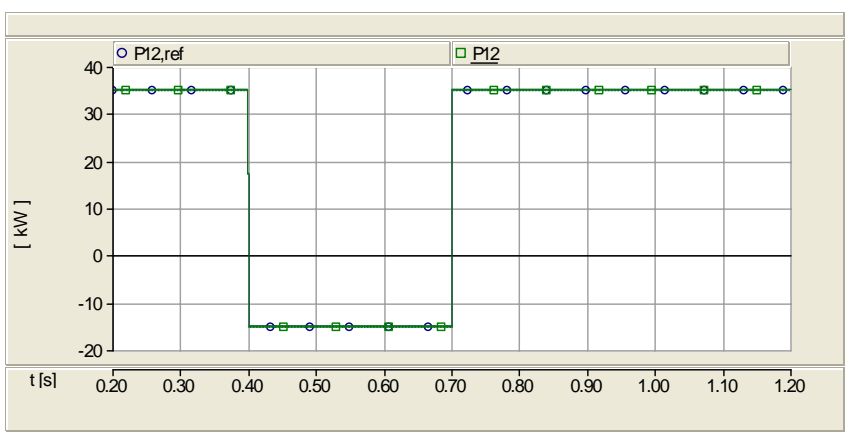

Fig. 5. Transfer power reference and power of DC/DC ICC

The DC bus voltages of DC $\mu \mathrm{G} 1$ and $D C \mu G 2$ are illustrated in Fig. 6. Instantaneous active powers of the network converters in DC $\mu \mathrm{G} 1$ and $\mathrm{DC} \mu \mathrm{G} 2$ are shown in Fig. 7.

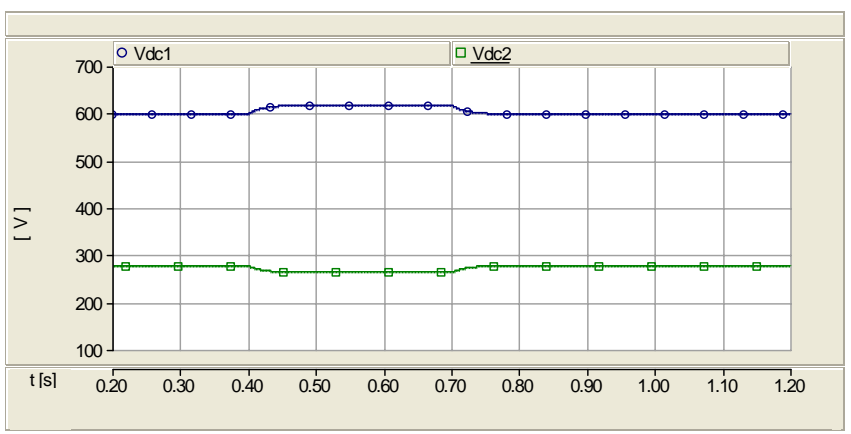

Fig. 6. DC bus voltage of $\mathrm{DC} \mu \mathrm{G} 1$ and $\mathrm{DC} \mu \mathrm{G} 2$

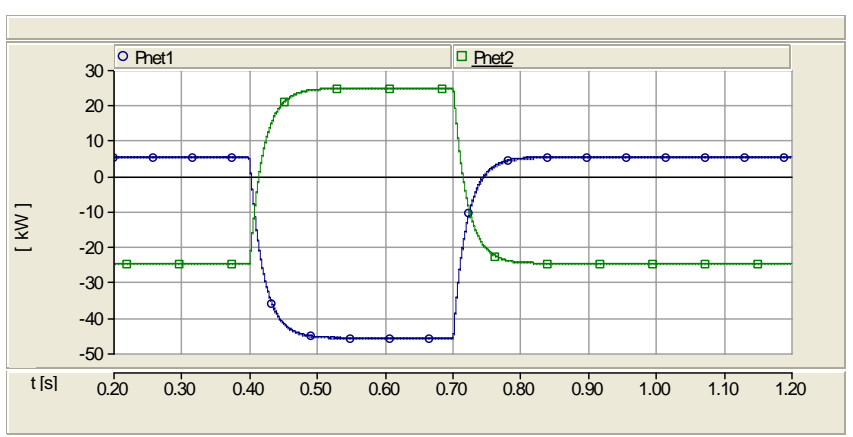

Fig. 7. Active power of the network converters

In the steady state condition, we have $P_{\text {Net1 }}=5.25 \mathrm{~kW}$, $V_{d c 1}=597.97 \mathrm{~V}, P_{\text {Net } 2}=-24.75 \mathrm{~kW}$ and $V_{d c 2}=278.35 \mathrm{~V}$. These results can be verified by (2). As shown in Fig. 6, the DC bus voltages are maintained within specified limits. This indicates the good performance of the DC voltage droop controller. As shown in Fig. 5, the active power of 
the DC/DC ICC effectively follows the scheduled transfer power reference. This indicates the effectiveness of the proposed control system for the DC/DC ICC.

\section{B. Changes in DG and Load Power of DC $\mu G s$}

In this section, the system performance under changes in active powers of the DG resource and the load in both $\mathrm{DC} \mu \mathrm{Gs}$ is studied. The scheduled transfer power reference is assumed constant. Fig. 8 illustrates $P_{12 \text {,ref }}$ and the instantaneous active power of the DC/DC ICC.

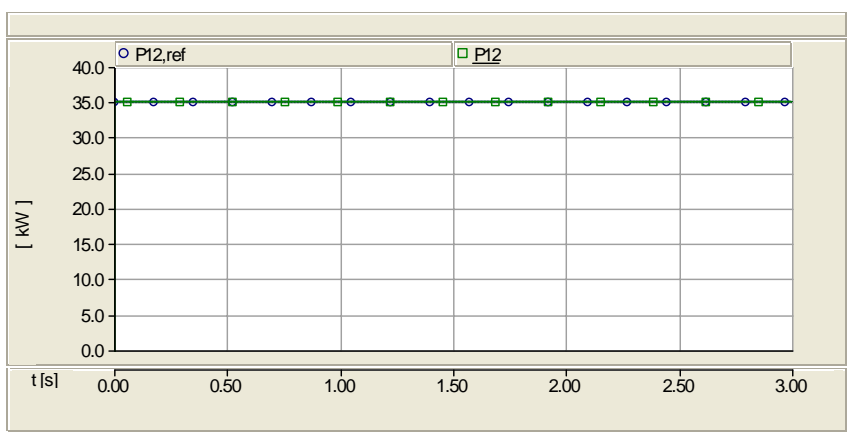

Fig. 8. Transfer power reference and power of DC/DC ICC

The active powers of the DG resource, the load power and the network converter of DC $\mu \mathrm{G} 1$ and DC $\mu \mathrm{G} 2$ are illustrated in Fig. 9 and Fig. 10, respectively.

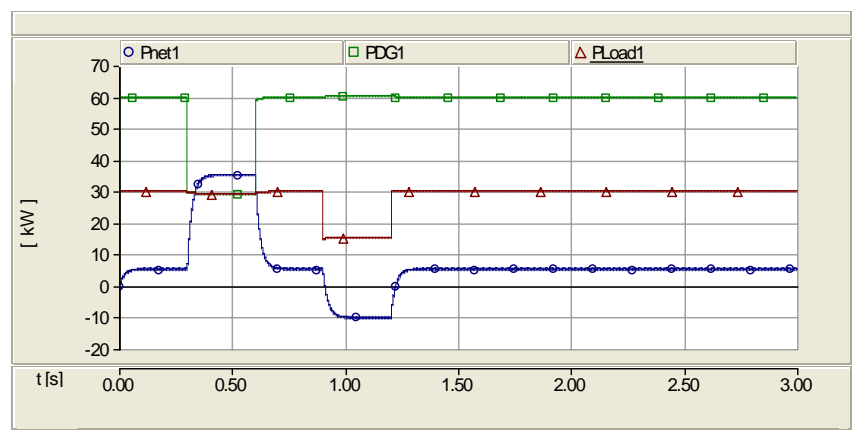

Fig. 9. Power of DG, load and network converter of $D C \mu G 1$

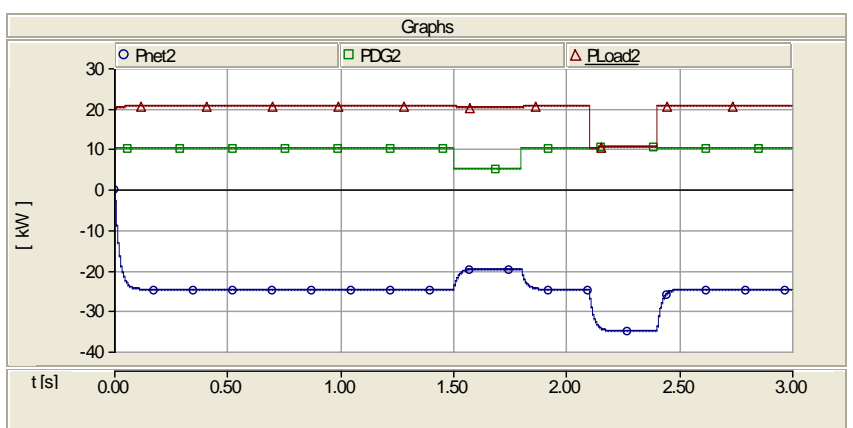

Fig. 10. Power of DG, load and network converter of DC $\mu \mathrm{G} 2$

The DC bus voltages of $\mathrm{DC} \mu \mathrm{G} 1$ and $\mathrm{DC} \mu \mathrm{G} 2$ are shown in Fig. 11.

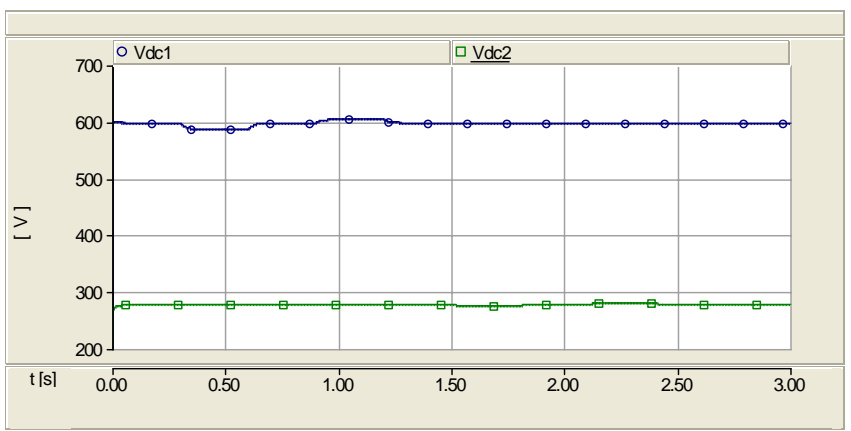

Fig. 11. DC bus voltage of $\mathrm{DC} \mu \mathrm{G} 1$ and $\mathrm{DC} \mu \mathrm{G} 2$

In the steady state condition, the obtained results are the same as the previous simulation and therefore they are also verified by (2). As shown in Fig. 11, the DC bus voltages are maintained within specified limits. This indicates the effectiveness of the DC voltage droop controller. Furthermore, it can be seen that the DC bus voltage of either $\mathrm{DC} \mu \mathrm{G}$ is not changed due to changes in the DG or load power in the other $\mathrm{DC} \mu \mathrm{G}$. As a result, disturbances in one $D C \mu G$ have no effect on the other DC $\mu G$. This indicates the good performance of the proposed control system for the DC/DC ICC in the cancellation of interactions between DC $\mu \mathrm{Gs}$. As illustrated in Fig. 8, the instantaneous active power of the DC/DC ICC is constant during changes in DG or load power of both DC $\mu \mathrm{Gs}$. This indicates the effectiveness of the proposed control system for the DC/DC ICC in the exact regulation of power transfer between the $\mathrm{DC} \mu \mathrm{Gs}$.

\section{Conclusion}

The operation and control strategies for the interconnection of $\mathrm{DC} \mu \mathrm{Gs}$ have not been studied in previous researches. In this paper, a suitable control strategy has been developed for a DC/DC voltage source converter which interconnects two DC $\mu G$ s. The proposed control system for this converter incorporates an instantaneous power-based reference current calculator for a two level hysteresis current regulator. Also, a large signal model of DC $\mu \mathrm{Gs}$ has been developed which can effectively be used to study the interactions of DC $\mu \mathrm{Gs}$ in a DC power park. This paper also proposes a new approach to design the AC network interface converter controller which eliminates the need for costly power leveling units and overcomes unexpected power changes in DCHGs. Simulation results indicate that the proposed control strategy can properly regulate the instantaneous power transfer and can eliminate the interactions between interconnected $\mathrm{DC} \mu \mathrm{Gs}$.

\section{References}

[1] J. Eto, V. Budhraja, C. Martinez, J. Dyer, M. Kondragunta, "Research, Development, and Demonstration needs for Large-Scale, ReliabilityEnhancing, Integration of Distributed Energy Resources", Proceedings of the 33rd Annual Hawaii International Conference on System Sciences, Jan. 2000.

[2] M. Mahmoodi, G. B. Gharehpetian, M. Abedi, R. Noroozian, "Control Systems for Independent Operation of Parallel Connected DG Units in 
Distribution DC Systems", IEEE International Power and Energy Conference (PECon'06), Nov. 2006.

[3] M. Mahmoodi, G. B. Gharehpetian, M. Abedi, R. Noroozian, "A Powerful Control Strategy for Source Converters and a Novel LoadGeneration Voltage Control Scheme for DC Voltage Determination in DC Distribution System", IEEE International Power and Energy Conference (PECon'06), Nov. 2006.

[4] Y. Ito, Y. Zhongqing, H. Akagi, "DC Micro-grid Based Distribution Power Generation System", The 4-th International Conference on Power Electronics and Motion Control, IPEMC, Aug. 2004.

[5] M. Brenna, E. Tironi, G. Ubezio, "Proposal of a Local DC Dstribution Network with Distributed Energy Resources", 11th IEEE International Conference on Harmonics and Quality of Power, Sep. 2004.

[6] P. Karlsson, J. Svensson, "DC Bus Voltage Control for a Distributed Power System", IEEE Transactions on Power Electronics, Vol. 18, No. 6, Nov. 2003.

[7] B. K. Johnson, R. Lasseter, "An Industrial Power Distribution System Featuring UPS Properties", IEEE Power Electronics Specialists Conference, PESC 1993.

[8] A. L. Dimeas, N. D. Hatziargyriou, "Operation of a Multiagent System for Microgrid Control", IEEE Transactions on Power Systems, Vol. 20, No. 3, Aug. 2005.

[9] M. P. Kazmierkowski, L. Malesani, "Current Control Techniques for Three-Phase Voltage-Source PWM Converters: A Survey", IEEE Transactions on Industrial Electronics, Vol. 45, No. 5, Oct. 1998, pp 691703. 